\title{
A REANÁLISE DOS CLÍTICOS ME E TE EM ESTRUTURAS DE REDOBRO PRONOMINAL NO DIALETO MINEIRO
}

\begin{abstract}
Ricardo Machado Rocha*
Resumo: Neste artigo, analisamos a ocorrência das formas pronominais me e te em estruturas de redobro. Argumentamos que, em alguns falares mineiros, essas formas estão sendo reanalisadas como prefixos de concordância para os traços de pessoa [+falante] e [+destinatário]. O trabalho se desenvolve dentro da abordagem minimalista. Lançamos mão também de alguns conceitos de gramaticalização.

Palavras-chave: Pronomes pessoais; clíticos redobros; concordância; reanálise; gramaticalização.

Abstract: This study examines the occurrence of the pronoun forms $m e$ and te in clitic doubling structures. We argue that in some nonstandard Brazilian Portuguese dialects from the state of Minas Gerais, these forms are being reanalyzed as prefixes of agreement for the person features [+speaker] and [+addressee]. The analysis is developed within the minimalist approach. We used also some concepts of grammaticalization.
\end{abstract}

Keywords: Personal pronouns; clitic doubling; agreement; reanalysis; grammaticalization.

\footnotetext{
* Universidade Federal de Minas Gerais.
} 


\section{Introdução ${ }^{1}$} (2010): ${ }^{2}$

Comparem-se os seguintes exemplos, extraídos de Ramos
a. eles carregaro eu
b. ele me levou

Incontáveis trabalhos têm investigado um fenômeno patente do português brasileiro (PB) quanto à realização pronominal: o uso das antigas formas nominativas em praticamente todos os contextos sintáticos (MACHADO ROCHA, 2010; RAMOS, 2009; CARVALHO, 2008; GONÇALVES, 2003, KATO, 1999; entre vários outros). Em Machado Rocha (2010), defendemos que o PB parece estar caminhando na direção de preferir pronomes default ${ }^{3}$ como em (1a), uma vez que eles podem ocorrer em todos os contextos sintáticos, ao contrário dos pronomes oblíquos, como em (1b), que requerem movimento para posição de próclise. ${ }^{4}$

No entanto a ocorrência de redobros levanta um problema. Veja-se o exemplo (2) a seguir, extraído de Ramos (2010):

(2) eles me carregaro eu.

\footnotetext{
${ }^{1}$ Versão atualizada de trabalho anteriormente publicado em: Anais do SILEL, Uberlândia, v. 2, n. 2, p. 1-17, 2011.

${ }^{2}$ Dados de fala da cidade de Piranga. Conjunto de entrevistas coletadas por Mônica Alkmin e Elaine Chaves.

${ }^{3}$ Um pronome DP default seria não especificado quanto à categoria gramatical Caso $(e u, \operatorname{voc} \hat{e}(s)$, ele $(a)(s)$, nós, a gente, o(a) $(s)$ senhor $(a)(s))$, em oposição a um pronome KP oblíquo, que representa um forma mais especificada para a categoria gramatical Caso ( $m e$, mim, comigo, te, nos). Os primeiros teriam ocorrência irrestrita em todos os contextos sintáticos; os últimos ocorreriam em contextos específicos. Para detalhes sobre a proposta de que a categoria gramatical Caso projetaria um núcleo funcional específico, com implicações para a forma pronominal, ver Machado Rocha (2010).

${ }^{4}$ A construção (1a) sofre, evidentemente, alguns estigmas em falares que não os dialetos sob nosso enfoque. Para estender a análise ao PB como um todo, podemos comparar estruturas como "eles carregaram você / eles te carregaram", em que a forma default você é amplamente aceita.
} 
$\mathrm{O}$ uso de estruturas pronominais redobradas com as formas me e te são muito comuns em vários falares de Minas Gerais. Vejam-se alguns exemplos, extraído de Ramos (2010):

(3) a. Eu vou te jogá ocê no fogo

b. a prima dela não me queria $e u$ mais

c. tinha cinco médico lá me olhano $e u$ assim

d. tem vez que es não gosta muito de me deixá eu ficá lá

e. cê pode entrá que eu te ajudo ocê no que eu pudé

f. se uma hora acha um que te acerta ocê

g. aí começô a me xingá eu lá dentro

h. aí ele $m e$ começo a me xingá eu de maria-vai-com-asoutras

i. aí mais tarde ele me liberô ieu pa trabaiá no mei do pessoal

As questóes que esses dados nos colocam podem ser formuladas de seguinte maneira:

(i) Por que ocorrem redobros, se o pronome default é capaz de realizar o objeto completamente? Em outras palavras, por que se realizam estruturas como "eles me carregaro $e u$ ", se uma estrutura como "eles carregaro $e u$ " é realizada pelos mesmos falantes da anterior e, por isso, perfeitamente gramatical nesse falar?

(ii) Por que ocorrem redobros para a $1^{\mathrm{a}}$ e a $2^{\mathrm{a}}$ pessoas pronominais, mas não para a $3^{\text {a }}$ ?

(4) a. a prima dela não me queria eu mais (RAMOS, 2010)

b. Eu te amo você. (DINIZ, 2007)

c. *Eu $o$ vi ele.

Procuramos responder a essas questões dentro da abordagem minimalista (CHOMSKY, 1995, 1998, 1999, 2005), recorrendo também a alguns conceitos de gramaticalização como propostos em Roberts \& Roussou (2003). O artigo se organiza da seguinte forma: na seção 2, tratamos das relações entre as estruturas de redobro e a interpretação das formas pronominais; na seção 3 , discutimos o processo de reanálise dos pronomes clíticos como prefixos de concordância, apresentando testes e evidências; e na seção 4 apresentamos as conclusões do trabalho. 


\section{O redobro pronominal e a interpretação dos pronomes}

A entrada dos pronomes tardios você, a gente e o senhor na série dos pronomes pessoais parecem indicar a tendência do paradigma de pronomes do PB de se regularizar para conter apenas formas default para Caso. Essa regularização estaria levando pronomes clíticos a perderem espaço no paradigma. Vários pronomes clíticos deixaram de ser usados a partir da segunda metade do século passado, como tem demonstrado extensivamente a literatura (KATO, 1993; CYRINO, 1994; GALVES \& ABAURRE, 1996; CYRINO \& REICH, 2002; entre vários outros).

Por outro lado, como apontam alguns trabalhos recentes (DINIZ, 2007; MACHADO ROCHA, 2010), os clíticos me e te se mantêm firmes no léxico, em estruturas simples e em estruturas de redobro. Argumentamos que esses redobros são realizados por necessidades interpretativas / computacionais de um sistema pronominal em estado de rearranjo. Parece ser empiricamente sustentável que o uso dos redobros no $\mathrm{PB}$ atual começa a preencher lacunas no sistema integrado do paradigma pronominal e das desinências de concordância. Como atesta a literatura, uma nova marca morfológica de concordância surge historicamente apenas em contextos do paradigma em que a marca pré-existente já não é distintiva (FUß, 2005 retomando GIVÓN, 1976; SIEWIERSKA, 1999).

Carvalho (2008) argumenta que vários pronomes pessoais do PB podem apresentar ora leitura definida, ora leitura arbitrária/ indefinida. ${ }^{5}$ Vejam-se os exemplos:

\footnotetext{
${ }^{5}$ Um pronome apresenta leitura arbitrária/indefinida quando não possui um referente específico/definido, mas, ao contrário, pode se referir a qualquer indivíduo. Pela comparação entre os exemplos (5) e (6), percebe-se que o pronome $e u$, em (5), não se refere à primeira pessoa do discurso, mas tem referência indefinida, podendo ser substituída por formas como alguém, qualquer pessoa, como exemplificado em (6). Para Carvalho (2008, p. 67), o que acarreta a leitura arbitrária de um pronome é a ausência de traços definitude em sua composição."
} 
(5) $E u$ começo a fumar um cigarro hoje, amanhã eu experimento $\mathrm{X}$.

[Contexto: um agente de controle de drogas entorpecentes sendo entrevistado por um apresentador de TV]. (CARVALHO, 2008, p. 83)

Como assinala Carvalho (2008), o pronome eu nesse exemplo tem leitura arbitrária e pode ser substituído por outra forma de leitura arbitrária/indefinida:

(6) Você / a gente / alguém começa a fumar um cigarro hoje, amanhã você / a gente / alguém experimenta $\mathrm{X}$. (CARVALHO, 2008, p. 83)

Em posição de objeto, pronomes default permitem igualmente a leitura arbitrária. Construções de redobro, por outro lado, parecem menos compatíveis com a leitura arbitrária, como mostra (7b).

(7) a. E quando você tenta sair dessa vida, ninguém ajuda você não.

b. E quando você tenta sair dessa vida, ninguém te ajuda você não. (MACHADO ROCHA, 2010, p. 104)

Dados de fala dos corpora do Projeto Mineirês (RAMOS, 2010) ${ }^{6}$ parecem confirmar essa hipótese, como se vê nos exemplos (8a-c):

(8) a. Cada dia que cê trabalha, cê conhece eles melhor... (Respondendo à pergunta do entrevistador: "Os meninos no seu serviço são encapetados?")

b. Cê num pode abaxá pra ês... P'que se não ês ... Sentam mesmo...

c. Tudo lá é muito caro, tudo lá é mais... Sabe?... Com muito luxo... Agora uma coisa eu vou te falá com'cê... Ês gosta muito de luxo assim...

\footnotetext{
${ }^{6}$ Dados de fala da cidade de Belo Horizonte. Conjunto de entrevistas coletadas por Leonardo Araújo.
} 
Perceba-se que em (8a-b), o pronome cê não faz referência ao interlocutor, mas possui uma referência arbitrária, indefinida, significando "alguém", "qualquer pessoa". Contrariamente, em (8c), em que ocorre o redobro pronominal, o informante se dirige especificamente ao entrevistador.

A arbitrariedade na interpretação dos pronomes do português atual parece estar associada principalmente a divergências entre traços formais de número e pessoa, responsáveis pela concordância sintática dos pronomes, e a interpretação semântica de número e pessoa do pronome (D'ALESSANDRO, 2006; CRUSCHINA, 2009). Para Carvalho (2008), a leitura arbitrária de um pronome é resultado da subespecificação de traços da categoria pessoa, nos termos de Béjar (2003).

Independentemente da opção teórica que se adote, pode-se assumir como dado empírico que alguns pronomes permitem leitura arbitrária, enquanto outros a proíbem. Notadamente, os pronomes de $1^{\mathrm{a}}$ e $2^{\mathrm{a}}$ pessoas permitem leitura arbitrária, enquanto os de $3^{\mathrm{a}}$ a proíbem.

(9) a. Hoje eu / você / a gente fumo(a) um cigarro, amanhã eu / você / a gente experimento(a) X. (leitura arbitrária)

b. Hoje ele fuma um cigarro, amanhã ele experimenta X. (*leitura arbitrária)

(MACHADO ROCHA, 2010, p. 105)

Duas distinções na constituição e na sintaxe dos pronomes de $1^{\mathrm{a}}$ e $2^{\mathrm{a}}$ pessoas, de um lado, e de $3^{\mathrm{a}}$ pessoa, de outro, podem ser apontadas:

i) Os pronomes de $1^{\mathrm{a}}$ e $2^{\mathrm{a}}$ pessoas possuem os traços [falante] / [destinatário], enquanto os pronomes de $3^{\mathrm{a}}$ são não especificados para esses traços ${ }^{7}$ (KERSTENS, 1993; KOENEMAN, 2000; HARLEY \& RITTER, 2002; dentre outros):

\footnotetext{
${ }^{7}$ A ideia da $3^{\text {a }}$ pessoa subespecificada para os traços de pessoa remonta a Benveniste (1956), primeiro a defender que a os pronomes de $3^{a}$ pessoa são a não-pessoa.
} 
$1^{\text {a }}$ pessoa
$[+$ falante $]$
$[-$ destinatário $]$ $2^{\mathrm{a}}$ pessoa

[- falante]

[+ destinatário $]$ $3^{\mathrm{a}}$ pessoa

[-falante]

[- destinatário]

(MACHADO ROCHA, 2010, p. 105)

ii) Pronomes de $3^{\mathrm{a}}$ pessoa precisam necessariamente ter um antecedente no discurso ou um referente dêitico, enquanto os pronomes de $1^{\mathrm{a}}$ e $2^{\mathrm{a}}$ não requerem um antecedente e podem ter a leitura dêitica anulada, quando sua referência é arbitrária:

(10) a. E você acha que empresa de telefone está preocupada em ajudar eu / você / nós / a gente?

b. E você acha que empresa de telefone está preocupada em ajudar ele? (MACHADO ROCHA, 2010, p. 105)

Perceba-se que os pronomes em (10a) permitem leitura arbitrária, enquanto o pronome ele, em (10b), proíbe tal leitura. Em (10a), qualquer um dos pronomes em destaque pode ser interpretado como indefinido. Em (10b), porém, o pronome ele precisa, necessariamente, de possuir um antecedente no discurso (como o João) ou um referente dêitico (alguém na situação comunicativa) e não permite uma interpretação indefinida. Ora, se a série de $3^{a}$ pessoa é não especificada para os traços [falante] / [destinatário], sua realização preenchida ocorre justamente para atender a necessidades discursivas ou dêiticas, uma vez que o pronome nulo de $3^{\text {a }}$ pessoa (pro, segundo Kato (1993)) também permite leitura arbitrária:

(11) E você acha que empresa de telefone está preocupada em ajudar pro?

(MACHADO ROCHA, 2010, p. 105)

Retomemos, agora, os exemplos iniciais (1a-b) e (2), repetidos aqui como (12a-c):

(12) a. eles carregaro eu

b. ele me levou

c. eles me carregaro eu. 
Se assumirmos como correto que os pronomes de $1^{\mathrm{a}}$ e $2^{\mathrm{a}}$ pessoas permitem leitura arbitrária, enquanto os pronomes de $3^{\mathrm{a}}$ pessoa a proíbem, temos uma explicação para a ocorrência de redobros com as formas me e te e a não-ocorrência de redobros para a $3^{\mathrm{a}}$ pessoa:

1) A tendência do PB atual é para a realização do objeto com o pronome default, a exemplo de (12a), como argumentamos no início deste trabalho.

2) Em contextos discursivos dialógicos, o uso das formas $m e$ e te inibe a referência arbitrária da $1^{\mathrm{a}} \mathrm{e}$ da $2^{\mathrm{a}}$ pessoas.

(13) a. Empresa de telefone não está preocupada em ajudar você não. (leitura arbitrária)

b. Empresa de telefone não está preocupada em te ajudar você não. (leitura definida)

3) Não ocorrem redobros de $3^{a}$ pessoa, porque a realização das formas lexicais de $3^{a}$ não têm a ver com traços [falante] / [destinatário], mas com a referência dêitica ou com correferência discursiva.

(14) Empresa de telefone não está preocupada em ajudar ele. (ele necessariamente associado a um antecedente ou a um referente dêitico)

4) Para a indefinição/arbitrariedade na série de $3^{\mathrm{a}}$ pessoa, usa-se o pro.

(15) Empresa de telefone não está preocupada em ajudar pro.

5) Podemos assim afirmar que, para falantes que realizam redobros, os clíticos me e te são sempre redobros, ora de pronomes lexicais, ora de pro.

(16) a. Me ajuda $e u$.

b. Me ajuda pro.

6) Levantamos a hipótese de que a ocorrência de apenas a forma lexical do pronome (ajuda eu) acontece em contextos discursivos em que outros elementos do discurso bloqueiam a leitura arbitrária e, assim, o redobro é dispensável. 
(17) a . Ajuda eu aqui.

b. É pra você ajudar eu mesmo.

Nossa hipótese para a ocorrência do redobro, então, é que lacunas nos traços de definitude dos pronomes default eu e você, em posição de objeto, estão sendo compensadas pelas formas me e te, que passam a compor, no paradigma integrado de pronomes e marcas de concordância, a função de concordância de objeto para os traços [falante] / [destinatário]. Evidentemente, esse fenômeno precisa ser enxergado como uma variação dialetal, nos termos de Kroch (1989) e Kroch \& Taylor (1994, 1997). Assumimos assim que alguns falares do PB possuem a gramática dos clíticos (G1), enquanto outros possuem a gramática dos redobros (G2). Além disso, assumimos que, na gramática dos falantes de redobro, as formas me e te são sempre redobros, ora concordando com o pronome lexical, ora concordando com pro. ${ }^{8}$

$\mathrm{Na}$ próxima seção, vamos levantar argumentos para a hipótese de que os clíticos me e te estão sendo reanalisados como marcas de concordância. Dessa maneira, na gramática do redobro

\footnotetext{
${ }^{8}$ Uma pergunta que surge diante de nossas hipóteses é a seguinte: por que não ocorrem redobros para a $1^{a}$ e a $2^{a}$ pessoas do plural, uma vez que também possuem em sua constituição os traços [+falante] [+destinatário], respectivamente? Não temos notícias de redobros para as pessoas do plural em nenhum falar do PB. Nos corpora analisados, não há ocorrências das formas nós e vocês com leitura arbitrária/indefinida. Podemos aventar que, se o redobro se justifica exatamente para desfazer a possibilidade da interpretação arbitrária do pronome, a não-ocorrência do redobro com as formas de plural se explica pelo fato de que essas formas jamais apresentam interpretação arbitrária. A definitude obrigatória das formas nós e vocês sugere uma relação imbricada entre traços de número e definitude, mas essas questões fogem ao escopo deste trabalho. A forma a gente ocorre em contextos de arbitrariedade, mas requer uma análise diferenciada em relação ao pronome nós, em vista de suas propriedades morfossintáticas de singular, ainda que semanticamente se refira ao plural. Várias outras questões, como a provável indisponibilidade da forma clítica vos, desusada no $\mathrm{PB}$, e a perda de espaço da forma nos para a forma default a gente precisam ser investigadas. Deixamos todas essas questões para pesquisas futuras.
} 
(G2) não haveria pronomes casualmente especificados/clíticos, mas apenas pronomes default e as formas resistentes prep. + mim e comigo. Os clíticos, em G2, teriam sido reanalisados como prefixos de concordância.

\section{A reanálise dos clíticos redobros como prefixos de concordância}

Distinguir clíticos de marcas de concordância tem se revelado uma tarefa difícil. As construções de redobro variam estruturalmente de uma língua para outra (ROBERGE, 1990 apud COURNANE, 2008) e um teste que se aplica a uma dada língua pode não ser adequado a outra. Além disso, o processo de gramaticalização que leva um pronome a se tornar uma marca de concordância é composto de várias etapas não necessariamente coincidentes para todas as línguas (COURNANE, 2008). Para Lopes (2007), na perspectiva da aquisição da linguagem, clíticos e elementos de concordância oferecem problemas semelhantes para a criança, o que leva essa autora a rotular ambos como elementos de concordância, em certo sentido.

Uma perspectiva mais recente e mais abrangente sobre a reanálise de pronomes como marcas de concordância pode ser encontrada em Fuß (2005), desenvolvida dentro de pressupostos minimalistas e do quadro da Morfologia Distribuída (HALLE \& MARANTZ, 1993, 1994).

Fuß (2005) adota várias ideias sobre gramaticalização propostas em Roberts \& Roussou (2003). Um de seus argumentos centrais, contrariando a visão tradicional de Givón (1976), é que a reanálise de pronomes como marcas de concordância não é restrita a um único contexto sintático. Para haver esse tipo de reanálise, Fuß (2005) argumenta que é preciso basicamente uma "confusão" na interpretação de uma dada estrutura, geralmente motivada por lacunas de paradigma. 
Fuß (2005) aponta uma série de condições, estabelecidas a partir de sua extensa pesquisa interlinguística, para que um clítico seja reanalisado como marca de concordância. A primeira delas é a necessidade de adjacência ao verbo:

(18) Restrição de adjacência

Um pronome clítico pode ser reanalisado como um afixo de concordância do verbo, apenas se o clítico é diretamente adjacente ao verbo. (FUß, 2005, p. 140)

Como aponta Cournane (2008), a restrição sobre adjacência para a reanálise faz sentido intuitivamente: se a concordância é entendida como local na sintaxe, espera-se que marcas de concordância sejam sempre adjacentes a seus hospedeiros. Dessa forma, quando um pronome clítico aparece sempre numa posição fixa de adjacência ao verbo, essa situação facilita a reanálise do pronome como marca de concordância.

Como visto na seção anterior, é exatamente nessa situação que encontramos as ocorrências das formas me te nos corpora analisados. Como se sabe, a próclise é uma tendência decisiva no PB (MATTOSO CÂMARA Jr., 1970; GALVES \& ABAURRE, 1996; MARTINS, 2003; dentre outros).

Outra condição sobre esse tipo específico de reanálise é a identificação de traços:

(19) Identificação de traços

A reanálise de um pronome clítico é possível apenas se a marca de concordância resultante é licenciada: (i) na sintaxe, por uma relação Agree ${ }^{9}$ local com um conjunto de

\footnotetext{
${ }^{9}$ Dentro do quadro minimalista (CHOMSKY, 1995, 1998, 1999), Agree ("concordar") é uma operação envolvida na valoração de traços que entram na derivação não valorados. Para que essa operação possa ocorrer, é preciso que haja match ("correspondência") entre os traços do elemento valorante (o alvo) e do elemento valorado (a sonda).
} 
traços-phi ${ }^{10}$ interpretáveis, ou (ii) na $\mathrm{MS},{ }^{11}$ como um morfema dissociado sob adjacência estrutural com um morfema de concordância licenciado. (FUß, 2005, p. 141)

Morfemas de concordância precisam ser licenciados na sintaxe. Assim um antigo clítico apenas pode ser reanalisado como marca de concordância, se a marca de concordância resultante puder ser licenciada em uma das duas formas propostas em (19i-ii). Como aponta Cournane (2008), essas suposições são relativamente fortes em termos de aquisição. A criança em fase de aquisição somente irá confundir um clítico com uma marca de concordância se esse elemento parecer licenciado, exigência natural da Gramática Universal.

O match $\boldsymbol{b}^{12}$ dos traços de pessoa [falante] / [destinatário] é relevante para a concordância que estamos propondo. Nos prefixos me e te, esses traços seriam interpretáveis, especificados como [+]. Por outro lado, as formas default eu e você podem ocorrer subespecificadas para esses traços (CARVALHO, 2008). Entendemos aqui que, em estruturas com os pronomes default, é possível a leitura arbitrária para esses traços, exatamente por se tratar de formas subespecificadas. Numa estrutura de redobro, em que os traços [falante] / [destinatário] aparecem tanto no pronome default como nos prefixos me e te, a leitura arbitrária é desfavorecida. Nessa perspectiva, os prefixos reforçam a leitura definida dos pronomes e bloqueiam a leitura arbitrária. Seria, então, estabelecida uma relação Agree local com os traços interpretáveis [falante] e [destinatário], satisfazendo assim a exigência (19i).

Outra exigência para a reanálise é a preservação da estrutura argumental:

${ }^{10}$ Grosso modo, na tradição chomskyana, traços-phi são traços de pessoa, número e gênero.

11 Dentro do quadro da Morfologia Distribuída, Morpbological Structure (Estrutura Morfológica).

12 Ver nota 8. 
(20) Preservação da estrutura argumental

A reanálise de um pronome como uma marca de concordância precisa preservar a estrutura argumental do predicado. (FUß, 2005, p. 141)

Essa condição prediz que, para que a criança, em fase de aquisição, reanalise um pronome clítico como marca de concordância, o papel temático atribuído ao pronome clítico precisa ser reanalisado como sendo atribuído a outro elemento - a um redobro ou a um pro, por exemplo.

Como demonstramos na seção anterior, os dados que analisamos exibem exatamente esse tipo de contexto. Na gramática do falante de redobros (G2), como vimos nos dados apresentados, o papel temático é atribuído ao pronome default ou a um pro e, assim, a estrutura argumental se preserva:

(21) a. Me ajuda. (Me = tema) (G1)

b. Me ajuda $e u$. $(e u=$ tema $) \quad(\mathrm{G} 2)$

É preciso ter sempre em mente que, em nossa análise, pressupomos duas gramáticas em variação. Essa variação pode ser estabelecida de duas maneiras, conforme se adote uma perspectiva sincrônica ou uma perspectiva diacrônica.

Num enquadramento sincrônico, temos falantes de G1, que possuem em seu léxico pronomes clíticos especificados para Caso, como propusemos anteriormente. Nessa gramática, construções de redobro não são legítimas e são interpretadas como um desvio. Assim, falantes de G1 optariam por construções como eu te ajudo ou eu ajudo você, mas não produziam sentenças como eu te ajudo você. Para a G1, clíticos e pronomes default estariam em distribuição complementar, como detalharemos a seguir. Falantes de G2, por outro lado, não possuiriam esses pronomes clíticos no léxico, que figurariam reanalisados como marcas de concordância para os traços de pessoa [falante] / [destinatário]. As estruturas preferidas nessa gramática são as que tradicionalmente chamamos de redobro (eu te ajudo você). Uma sentença como eu te ajudo é interpretada por falantes da G2 como possuindo a realização de um pro na posição 
de objeto (eu te ajudo pro). Portanto a sequência eu te ajudo seria produtiva nas duas gramáticas, sendo analisada como uma cadeia apenas em G1.

Sob um enfoque diacrônico, G1 e G2 podem ser entendidas com etapas do processo de gramaticalização dos prefixos de concordância.

\subsection{Alguns testes relevantes}

Como pontuamos, testes para o estatuto de clíticos e marcas de concordância precisam ser considerados caso a caso, por dois motivos principais:

1) O processo de gramaticalização envolve etapas sucessivas e não obrigatórias, como proposto por Roberts \& Roussou (2003):

(22) Pronome independente $>$ pronome fraco $>$ pronome clítico $>$ afixo de concordância $>$ desinência de concordância

2) A estrutura de redobros não é idêntica em todas as línguas.

Alguns critérios mais rígidos não podem ser ignorados, como a restrição sobre a adjacência ao verbo, a fixação da posição de ocorrência e a equivalência de traços que estabelecerão a relação de concordância. Os clíticos redobrados nos dados do dialeto analisado atendem a essas três exigências, conforme vimos na seção anterior. Vamos considerar assim mais alguns testes secundários, a partir de Cournane (2008) e outros trabalhos com os quais ela dialoga, que servem como evidência para as etapas da gramaticalização dos prefixos me e $t e$.

\subsubsection{Distribuição complementar}

Cournane (2008) adverte que a distribuição complementar entre clíticos e DPs ${ }^{13}$ lexicais pode ser um teste com falhas para a

${ }^{13}$ DP $=$ Determiner Phrase ("sintagma determinante"). 
verificação do estatuto de um elemento como marca de concordância. Por outro lado, ainda que não possa ser tomado como uma confirmação do estatuto de marca de concordância de um dado elemento, a distribuição complementar aponta, ao menos, para um contexto favorecedor do processo de reanálise.

Perceba-se que, para falantes da G1 proposta em nossa abordagem, clíticos e pronomes default se encontram em distribuição complementar:

(23) Falantes de G1

a. Eu te ajudo.

b. Eu ajudo você.

c. *Eu te ajudo você.

Falantes de G2, por outro lado, não possuem esses mesmos elementos em distribuição complementar, para o quais o exemplo (c) acima é perfeitamente gramatical.

(24) Falantes de G2

a. Eu te ajudo você.

A coocorrência da forma te com o pronome você indica que o antigo clítico não possui mais o estatuto de argumento e que, por isso, é interpretado de outra maneira. Em nossa hipótese, a interpretação que te recebe em G2 é de prefixo de concordância para o traço [+destinatário], como expusemos anteriormente. A mesma análise se aplica à forma me, que funciona como prefixo de concordância para o traço [+falante].

\subsubsection{Visibilidade sintática}

Operações sintáticas se aplicam a clíticos, mas não a marcas de concordância. Marcas de concordância não podem se mover independentes de seus hospedeiros. Num certo sentido, esse é também um diagnóstico sobre a distribuição, uma vez que clíticos podem aparecer em diferentes posições em relação ao verbo, enquanto que a marca de concordância ocupa uma posição fixa. 
Porque o PB tem a próclise como regra principal tanto em G1 quanto em G2, a verificação do caráter das formas me e te pela comparação entre G1 e G2 se torna ineficaz. Mas, se comparamos a G2 como o português europeu (PE), em que, indubitavelmente, essas formas são clíticos com estatuto argumental, podemos tomar a visibilidade sintática como uma evidência de que, em G2, me e te são prefixos de concordância. Vejam-se os exemplos a seguir, extraídos de Magalhães (2006). Os exemplos na fonte consultada são com o clítico lhe, contextos em que também é possível a ocorrência dos clíticos me e te. Para tornar a comparação clara, vamos utilizar exemplos em que há te em lugar de lhe:

(25) $P E:^{14}$

a. Os alunos ofereceram-te todos flores.

b. Os alunos ofereceram-te também flores.

c. Todos os alunos te ofereceram flores.

d. Os alunos também te ofereceram flores.

e. O que te ofereceram os alunos?

Como se pode observar nos exemplos (25a-e), o PE, embora seja essencialmente enclítico, permite a próclise, sem qualquer sintoma de desvio, em alguns contextos.

Contrariamente, na G2 do PB, a ênclise das formas me e te são agramaticais ou degradadas:

(26) $P B / G 2$ :

a. ?/*Os alunos ofereceram-te todos flores.

b. ?/*Os alunos ofereceram-te também flores.

c. Todos os alunos te ofereceram pro flores.

c' Todos os alunos te ofereceram você flores

d. Os alunos também te ofereceram pro flores.

d'. Os alunos também te ofereceram você flores.

e. ?O que te ofereceram pro os alunos?

e'. O que que os alunos te ofereceram você?

(MACHADO ROCHA, 2010, p. 113)

\footnotetext{
${ }^{14}$ Exemplos de Brito, Duarte \& Matos (2003, p. 853) apud Magalhães (2006, p. 14-15).
} 
Os exemplos acima permitem afirmar que, ao contrário do PE, na G2 do PB as formas me e te não podem ocorrer em outra posição senão a de adjacência pré-verbal. Como vimos, a posição fixa é uma característica das marcas de concordância, o que nos leva assumir que me e te, na G2 do $\mathrm{PB}$, são prefixos verbais.

\subsubsection{Completude de paradigmas}

Cournane (2008) retoma um diagnóstico proposto por Zwicky \& Pullum (1983), que fazem a seguinte distinção: clíticos aparecem em paradigmas completos, enquanto que marcas de concordância apresentam lacunas e sincretismos no paradigma. Os exemplos oferecidos são clíticos sujeitos do francês em paralelo com as marcas de concordância do verbo:

\section{QUADRO 1}

Paradigma de clíticos-sujeito e paradigma de concordância em francês (canadense) padrão ${ }^{15}$

\begin{tabular}{|c|c|c|}
\hline & $\begin{array}{l}\text { Subject Clitic } \\
\text { Paradigm }\end{array}$ & $\begin{array}{l}\text { Etre Present Tense } \\
\text { Agreement Paradigm }\end{array}$ \\
\hline $1^{\text {st }}, S G$ & [3ㅣ] & [swi] \\
\hline $2^{\text {nd }} \cdot S G$ & [tv] & [e] \\
\hline $3^{\text {rd }}, S G, M$ & [il] & [e] \\
\hline $3^{\mathrm{rd}}, \mathrm{SG}, \mathrm{F}$ & {$[\varepsilon \mid$} & [e] \\
\hline $3^{\text {rd }}, S G$, Indef & โโิ] & [e] \\
\hline $1^{\text {st }}, \mathrm{PL}$ & [nu] & [som] \\
\hline $2^{\text {nd }}$, PL (or SG polite) & [vu] & [et] \\
\hline $3^{\text {rd }}, \mathrm{PL}, \mathrm{M}$ & {$[\mathrm{il}(\mathrm{z})]$} & [s \\
\hline $3^{\text {rd }}, \mathrm{PL}, \mathrm{F}$ & {$[\varepsilon l(z)]$} & [sธิ] \\
\hline
\end{tabular}

${ }^{15}$ Quadro extraído de Cournane (2008, p. 32). É preciso esclarecer que o trabalho lida com o francês canadense, daí existirem diferenças fonológicas em relação ao francês europeu. 
O Quadro 1 ilustra que, no francês canadense padrão, enquanto os clíticos-sujeito possuem formas distintas para cada pessoa, com formas específicas para gênero e número, as marcas de concordância exibem vários casos de sincretismos ou lacunas.

Essa mesma situação pode ser verificada na comparação entre os clíticos do PE e as formas reanalisadas do PB/G2:

QUADRO 2

Clíticos do $\mathrm{PE} v \boldsymbol{s}$. prefixos do $\mathrm{PB} / \mathrm{G} 2^{16}$

\begin{tabular}{|l|c|c|}
\hline & Clíticos do PE & Prefixos do PB/G2 \\
\hline $1^{\mathrm{a}}$ sing. & me & me \\
\hline $2^{\mathrm{a}}$ sing. & te & te \\
\hline $3^{\mathrm{a}}$ sing. & o/a/se/lhe & - \\
\hline $1^{\mathrm{a}} \mathrm{pl}$. & nos & - \\
\hline $2^{\mathrm{a}} \mathrm{pl}$. & vos & - \\
\hline $3^{\mathrm{a}} \mathrm{pl}$. & os/as/lhes & - \\
\hline
\end{tabular}

Como se pode observar, o paradigma de pronomes clíticos do PE exibe formas específicas para cada pessoa, com especificações para gênero/caso nas séries de $3^{a}$ pessoa. Os prefixos do $\mathrm{PB} / \mathrm{G} 2$ possuem formas apenas para a $1^{\mathrm{a}} \mathrm{e} \mathrm{a} 2^{\mathrm{a}}$ pessoas do singular, mais uma evidência em favor de que essas formas são prefixos de concordância.

\subsubsection{Concordância parcial}

A concordância parcial é uma propriedade de sistemas de concordância, mas não de paradigmas de clíticos (HAIMAN \& BENINCÀ, 1992; FUß, 2005, p. 133 apud COURNANE, 2008, p. 32). Em outras palavras, em construções com clítico redobrando um DP, é esperado que haja uma identidade completa de traços-phi e de Caso entre o clítico e o DP redobrado. Em relações de concordância, por

${ }^{16}$ Quadro extraído de Machado Rocha (2010, p. 114). 
outro lado, pode haver identificação apenas parcial entre a marca de concordância e o DP.

Os exemplos de redobro com clíticos típicos, oferecidos por Cournane (2008), são do espanhol. Exemplos do espanhol, com identidade completa de traços-phi e de Caso entre o DP redobrado e o clítico de redobro (seguidos aqui de glosa e tradução para o português), extraídos de Cournane (2008, p. 33):
a. La oían
a la gata. (SUÑER, 1988, p. 395-396)
a ouviam a a gata
"Eles ouviram a gata."
b. Lo vi a el. (URIAGEREKA, 1995, p. 80)
o vi a ele
"Eu o vi."

No par (27a-b), clítico e DP exibem identidade entre todos os traços-phi e de Caso: número, pessoa, gênero e Caso. Em (27a) o clítico la é acusativo, $3^{\mathrm{a}}$ pessoa, singular e feminino, bem como o DP a gata. Semelhantemente, em (27 b) o clítico lo é acusativo, $3^{\mathrm{a}}$ pessoa, singular e masculino, com os mesmos traços presentes no DP el.

Ao contrário dos clíticos, marcas de concordância podem estabelecer relações parciais de identidade de traços. Os exemplos de Cournane $(2008$, p. 33) para concordância de traços-phi entre sujeito e o verbo être são do francês (aqui com nossa tradução para o português):
a. Je [swi] / Nous [som] / Vous [et] "eu sou" "nós somos" "vocês são"
b. La fille / Le gars / On / Tu [e] "a menina" "o "cara"” "a gente" "você é"
c. Ils / Elles [s̃̃]
"eles" "elas são"

Cournane observa, a partir desses exemplos, que, em (28a), para o traço de pessoa, há completa identidade entre a marca de concordância e o sujeito do verbo être. Por outro lado, em (28b-c), há sincretismo no paradigma, e apenas duas formas [e], em (28b), 
e [̃̃], em 28c são usadas. Portanto há instâncias de identidade apenas parcial em paradigmas de concordância como o do verbo être.

Retomando o Quadro 2 acima apresentado, podemos assumir, pela simples observação do paradigma de clíticos do PE, que, numa estrutura de DP redobrado por clítico, haverá concordância completa para traços-phi e de Caso, uma vez que há formas específicas para pessoa, número, gênero e Caso:

(29) a. Viram-na a ela no cinema ontem.

b. Agradeci-lhe a ele pela ajuda.

(SILVA, 2008, p. 5)

Os clíticos do PE, como se pode observar, estabelecem uma relação de identidade completa entre os traços-phi e de Caso com o DP redobrado. Em (29a), os traços $3^{\text {a }}$ pessoa, feminino, singular, acusativo aparecem tanto no DP ela como no clítico na. Em (29b), ocorre o mesmo, com identidade em ambos os elementos para os traços $3^{\text {a }}$ pessoa, masculino, singular, dativo.

Ao contrário, os prefixos de concordância do $\mathrm{PB} / \mathrm{G} 2$, por realizarem apenas os traços de pessoa [falante] / [destinatário], possuem formas apenas para a $1^{\mathrm{a}}$ e a $2^{\mathrm{a}}$ pessoas do singular $\mathrm{e}$ não fazem distinção para os casos dos pronomes DPs com os quais eles se associam (ACUS/DAT/ABL): ${ }^{17}$

(30) a. Eu vou te levá ocê lá (ACUS)

b. Deixa eu te perguntar ocê um negócio (DAT)

c. Eu num vou te falar com você que se você vier.... (ABL) (DINIZ, 2007, p. 49-50 apud MACHADO ROCHA, 2010, p. 117)

Como discutimos no início desta seção, apresentamos aqui alguns testes que julgamos compatíveis com a estrutura de redobro própria do $\mathrm{PB} / \mathrm{G} 2$, objeto de nossa análise, e com a etapa em que os prefixos me e te parecem se encontrar no processo de

${ }^{17}$ ACUS $=$ acusativo; DAT $=$ dativo $; \mathrm{ABL}=$ ablativo. 
reanálise. Nossa intuição é que essas marcas se encontrem num momento do processo de gramaticalização que Roberts \& Roussou (2003) vão chamar de afixo de concordância, por isso temos o termo que empregamos: me e te são prefixos de concordância no $\mathrm{PB} / \mathrm{G} 2$, e não pronomes clíticos.

Como adiantamos, não há um prefixo equivalente para a $3^{\mathrm{a}}$ pessoa, porque a $3^{a}$ pessoa é a não-marcada para os traços relevantes, ou seja, [-falante, -destinatário].

\section{Conclusões}

Neste trabalho, defendemos que, em alguns dialetos de Minas Gerais, as formas pronominais me e te estão sendo reanalizadas com prefixos de concordância para os traços [+falante] e [+destinatário]. A partir de vários trabalhos, argumentamos que lacunas nos traços de definitude dos pronomes default eu e você estão sendo compensadas pela inserção das formas me e te em estruturas de redobro. Mostramos também, a partir de vários testes, diversas evidências para o processo de reanálise das formas me e te como afixos de concordância. Assumimos a existência de uma gramática inovadora G2, em que não haveria pronomes clíticos, mas apenas pronomes default para Caso e as formas casuais resistentes prep. +mim e comigo. Em nossa perspectiva, a realização ou não dos prefixos de concordância vai depender de fatores discursivos e pragmáticos. Situações em que a leitura arbitrária do pronome é impedida por outros elementos linguísticos ou conversacionais, $o$ prefixo pode não se realizar. 


\section{Referências}

BÉJAR, S. Pbi syntax: a theory of agreement. Ph.D. dissertation University of Toronto, Toronto, 2003.

BENVENISTE, E. De la nature des pronoms: for Roman Jakobson. Haia: Mouton, 1956. [Repub.: In: . Problèmes de linguistique générale. Paris: Gallimard, 1966.] [Trad. port.: Problemas de lingüística geral. Campinas: Pontes, 1989. Vol. I.]

BRITO, A. M.; DUARTE, I.; MATOS, G. Tipologia e distribuição das expressões nominais. In: MATEUS, M. H. M.; BRITO, A. M.; DUARTE, I; FARIA, I. Gramática da língua portuguesa. 5. ed. ver. e aum. Lisboa: Caminho, 2003. p. 795-867.

CARVALHO, D. S. A estrutura interna dos pronomes pessoais em português brasileiro. Tese (Doutorado em Letras e Lingüística: Lingüistica) - UFAL, Maceió, 2008.

CHOMSKY, N. The minimalist program. Cambridge, Mass.: The MIT Press, 1995.

CHOMSKY, N. Minimalist inquires: the framework. MIT Occasional Papers in Linguistics, Cambridge, n. 15, 1998.

CHOMSKY, N. Derivation by phase. MIT Occasional Papers in Linguistics, Cambridge, n. 18, 1999.

CHOMSKY, N. On phases. Cambridge, Mass.: MIT, 2005. (Ms.)

COURNANE, A. The grammaticalization of subject clitics in Quebec French: an analysis of reanalysis. University of Toronto, 2008. (Ms.)

CRUSCHINA, S. The syntactic role of discourse-related features. Cambridge Occasional Papers in Linguistics, n. 5, p. 15-30, 2009.

CYRINO, S. M. L. O objeto nulo no português do Brasil: um estudo sintáticodiacrônico. Tese (Doutorado em Linguística) - UNICAMP, Campinas, 1994. CYRINO, S.M.L.; REICH, U. Uma visão integrada do objeto nulo no português brasileiro. Romanistiches Jabrbuch, Berlin, n. 52, p. 360-361, 2002.

D'ALESSANDRO, R. Syntactic and pragmatic features: a case study. Leitura, Maceió, n. 33, p. 185-202, 2006. 
DINIZ, C. Eu te amo você: o redobro de pronomes clíticos sob um abordagem minimalista. Dissertação (Mestrado em Estudos Linguísticos) - Faculdade de Letras, UFMG, Belo Horizonte, 2007.

FUß, E. The rise of agreement: a formal approach to the syntax and gramaticaliation of verbal inflection. Amsterdam: John Benjamins, 2005.

GALVES, C; ABAURRE, M. B. M. Os clíticos no português brasileiro: elementos para uma abordagem sintático-fonológica. In: CASTILHO, A. T. de; BASÍLIO, M. (Org.). Gramática do português falado. Campinas: Ed. da Unicamp, 1996. Vol. IV

GIVÓN, T. Topic, pronoun and grammatical agreement. In: Charles, L. (Ed.). Subject and topic. New York: Academic Press, 1976. p. 88-149.

GONÇALVES, R. S. O uso de pronomes de caso reto como complementos verbais: uma visão sócio-variacionista. Dissertação (Mestrado) - UFJF, Juiz de Fora, 2003.

HAIMAN, J.; BENINCÀ, P. The Rhaeto-Romance languages. Routledge: London and and New York, 1992.

HALLE, M.; MARANTZ, A. Distributed Morphology and the pieces of inflection. In: HALE, K.; KEYSER, S. J. The view from Building 20: essays in linguistics in honor of Sylvain Bromberger. Cambridge: MIT Press, 1993. p. 111-176.

HALLE, M.; MARANTZ, A. Some key features of Distributed Morphology. In: CARNIE, A.; HARLEY, H. MIT Working papers in linguistics: Papers on phonology and morphology, n. 21, p. 275-288, 1994.

HARLEY, H.; RITTER, E. A feature-geometric analysis of person and number. Language, v. 78, n. 3, p. 482-526, 2002.

KATO, M. A. Recontando a história das relativas. In: ROBERTS, I.; KATO, M. A. (Org.). Português brasileiro: uma viagem diacrônica. Campinas: Ed. da UNICAMP, 1993.

KATO, M. A. Strong pronous and weak pronominals in the null subject parameter. Probus, Berlin, v. 11, n. 1, p. 1-37, 1999.

KERSTENS, J. The syntax of number, person, and gender: a theory of phifeatures. Berlin: Mouton De Gruyter, 1993.

KOENEMAN, O. The flexible nature of verb movement. Ph.D. dissertation - Utrecht University, Utrecht, 2000. 
KROCH, A. Reflexes of grammar in patterns of language change. Language Variation and Change, v. 1, p.199-244, 1989.

KROCH, A; TAYLOR, A. Remarks on the XV/VX alternation to early Middle English. University of Pennsylvania, 1994. (Ms.)

KROCH, A; TAYLOR, A. Verb movement in Old and Middle English: dialect variation and language contact. In: KEMENADE, A. van; VINCENT, N. (Ed.). Parameters of morpbosyntatic change. Cambridge: Cambridge Univesity Press, 1997. p. 297-325.

LOPES, R.V. O que a aquisição inicial da sintaxe revela sobre parametrização? O caso dos objetos e estruturas afins. Letras de Hoje, Porto Alegre, v. 42, n. 1, p. 77-96, 2007.

MACHADO ROCHA, R. Morfossintaxe de caso nos pronomes pessoais do PB/MG atual. Dissertação (Mestrado em Estudos Linguísticos) Faculdade de Letras, UFMG, Belo Horizonte, 2010.

MAGALHÃES, T. M. V. O sistema pronominal sujeito e objeto na aquisição do português europeu e do português brasileiro. Tese (Doutorado em Linguística) - UNICAMP, Campinas, 2006.

MARTINS, M. A. Sobre o se indeterminador no português do Brasil: uma proposta morfológica. Working Papers em Linguística, Florianópolis, n. 7, p. ?, 2003.

MATTOSO CÂMARA Jr., J. Estrutura da língua portuguesa. 17. ed. Petrópolis: Vozes, 1970.

RAMOS, J. M. Senhor: um novo pronome? Salvador, 2009. (Comunicação apresentada no ROSAE: I Congresso Internacional de Linguística Histórica, realizado em Salvador, na Universidade Federal da Bahia, no período de 26 a 29 de julho de 2009).

RAMOS, J. M. Corpus do dialeto mineiro: textos orais; textos escritos dos séculos XVIII, XIX e XX. Belo Horizonte: UFMG/FAPEMIG/CNPq/ Núcleo de Pesquisa em Variação Linguística, 2010. (Versão eletrônica)

ROBERGE, Y. The syntactic recoverability of null arguments. Kingston: McGill-Queen's University Press, 1990.

ROBERTS, I.; ROUSSOU, A. Syntactic change: a minimalist approach to grammaticalization. Cambridge: Cambridge University Press, 2003. 
SIEWIERSKA, A. From anaphoric pronoun to grammatical agreement marker: why objects don't make it. Folia Linguistica, v. 33, n. 2, p. 225251, 1999.

SILVA, C. G. A. G. Assimetrias na aquisição de clíticos diferenciados em português europeu. Dissertação (Mestrado) - Faculdade de Ciências Sociais e Humanas, UNL, Lisboa, 2008.

SUÑER, M. The role of agreement in clitic-doubled constructions. Natural Language and Linguistic Theory, v. 6, p. 391-434, 1988.

URIAGEREKA, J. Some aspects of the syntax of clitic placement in Western Romance. Linguistic Inquiry, v. 26, p. 79-123, 1995.

ZWICKY, A. M.; PULLUM, G. K. Cliticization $v s$. inflection: English $n$ 't. Language, v. 59, n. 3, p. 502-513, 1983.

Recebido para publicação em 26 de outubro de 2011. Aprovado em 29 de novembro de 2011. 